\title{
Euskararen tempus-aspektu-modu sistemaren trataera formala
}

\author{
(A Formal Treatment \\ of the Basque Tense-Aspect-Modus System)
}

Ibon Coterón Agorria

IES Ategorri BHI

IbonKoteron@gmail.com

DOI: 10.1387/ekaia.17695

Jasoa: 2017-03-06

Onartua: 2017-07-11

Laburpena: Lan honetan trataera formal bateratu bat aurkeztuko da euskal aditz jokatuaren tempus, aspektu eta moduarentzat.

Hitz gakoak: tempusa, aspektua, modua, euskal aditza.

Abstract: In this work, an integral formal treatment of Basque verb tense, aspect and mood will be provided.

Keywords: tense, aspect, modus, Basque verb.

\section{SARRERA}

Adizki jokatuak erabiliz, hiztunok espazio semantiko konplexu batean kokatzen ditugu edonolako gertaerak (egoerak, jarduerak, jazokuntzak, lorpenak...), hizketa-egintzaren gunetik gertuago edo urrunago. Hizketa-egintzarena da lehen orientazio-puntua gertaeren kokatze prozesu horretan $-\mathrm{O}^{(1) \mathrm{S}}$, hots, Orientation(Speech-situation) - , baina bestelako orientazio-puntuak beharrezkoak dirateke. Halakoak marka morfologiko desberdinen bidez adieraz daitezke, dimentsio semantiko anitzoi erantzunez: tempusa, modua/modalitatea eta aspektua. 1. irudian eskema orokorra ikus daiteke: 


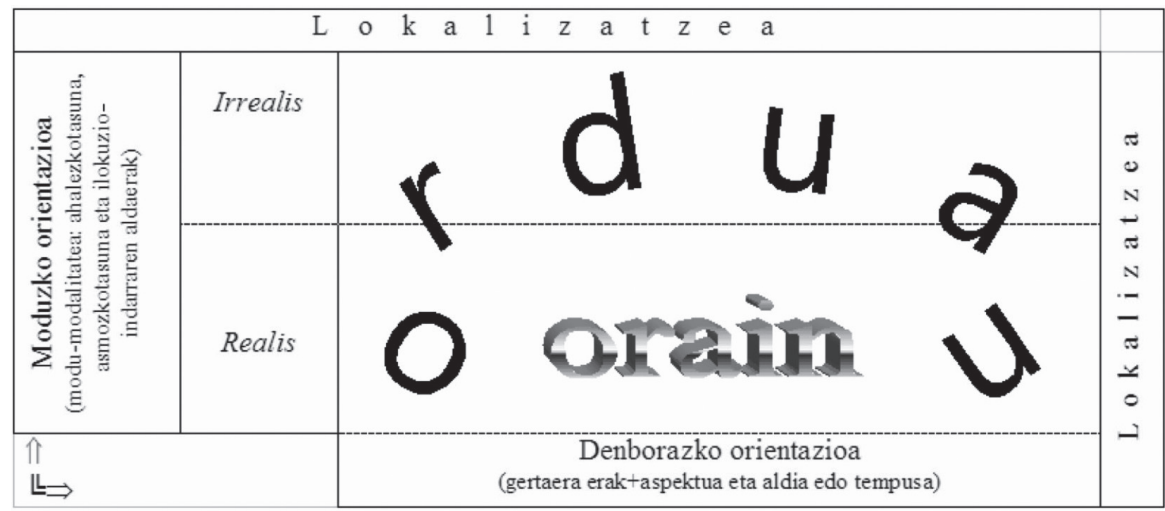

1. irudia. Gertaeren lokalizatzea moduzko eta denborazko orientazioen eremu semantikoan.

Orientazio-punturen batetik begiratu egiten zaio gertaerari. ' ${ }^{\prime}$ ' zeinuak ikuspuntua adierazteko erabiliz gero, zeinu hori beti agertuko da orientazio-puntu bati lotuta: Ô. Puntu horretatik gertaerari nola begiratzen zaion, aspektuari dagokio.

Ondoko atalean azalduko da hori. Hurrengoan, modua / modalitatearen eta tempusaren jorraketari ekingo zaio. Azkenengoak emaitzak laburbilduko ditu.

\section{GERTAERA-ERAK ETA ASPEKTU-OPERATZAILEAK}

Trataera honek Johansonena [1] du oinarri. Autore horren aburuz gertaera batek hiru fase nagusi izan ahal ditu - hasiera edo lehen muga, garapena edo ibilbidea, eta bukaera edo bigarren muga-, baina gertaera barneko fase-egitura zenbait modutan uler daiteke: aldakuntzarik (transformativity) barruratu gabe (esnaturik egon) edo halakoa barruratuz (eseri). Alde hori formalki adieraz daiteke tasun semantiko bitarren ohiko prozeduraz: $[-\mathrm{t}]$ aldakuntzarik gabekoentzat, $[+\mathrm{t}]$ aldakuntzadunentzat. Aldakuntzarik gabekoak dinamikotzat har daitezke, [+din] ([+dyn] Johansonen jatorrizko bertsioan) (ibili), edo estatikotzat, [-din] ([-dyn]) (euskalduna izan). Gainontzekoetan aldakuntza gerta daiteke hasiera gisa, [+ti] (etxerantz joan), edo bukaera gisa, [+tf] (etxera etorri); kasu honetan ibilbide nabari batekin, [-mom] (artikulu bat idatzi), edo horrelakorik gabe, [+mom] (eztanda egin). Esplizituki definiturik (Ikusi 1. taula): 
1. taula. Gertaera-erak bereizteko tasun semantikoak.

\begin{tabular}{c|l}
\hline$[ \pm \mathrm{t}]$ & aldakuntzazkotasunaren edo haren gabeziaren adierazpena \\
\hline$[ \pm \mathrm{ti}]$ & aldakuntza hasierako mugan den / ez den adierazpena \\
\hline$[ \pm \mathrm{tf}]$ & aldakuntza bukaerako mugan den / ez den adierazpena \\
\hline$[ \pm \mathrm{mom}]$ & gertaeraren mementozkotasunaren (edo kontrakoaren) adierazpena \\
\hline$[ \pm \mathrm{dyn}]$ & gertaeraren dinamismoaren (edo kontrakoaren) adierazpena \\
\hline
\end{tabular}

Horrez gain, gertaeraren osagaien kokaguneak formalki definitu behar dira (Ikusi 2. taula):

2. taula. Gertaeren eta haien faseen kokaguneen definizioak.

\begin{tabular}{|c|c|}
\hline $\mathrm{G}$ & $\begin{array}{l}\text { aditz-esaldiaren bidez adierazitako gertaeraren kokagunea edo lokali- } \\
\text { zatzea }\end{array}$ \\
\hline $\mathrm{O}$ & orientazio-puntua \\
\hline M & gertaeraren funtsezko / intereseko mugaren kokagunea \\
\hline I & gertaera-ibilbidearen kokagunea \\
\hline G & $={ }_{\text {def }} I \cup M$ \\
\hline $\mathrm{L}$ & $\begin{array}{l}\text { gertaeraren lokalizatze-puntua zentzu zabalean, G, M edo I-rekin iden- } \\
\text { tifikagarria }\end{array}$ \\
\hline$\alpha, \beta, \gamma \ldots$ & edozein G, O, M, I edo L-ren ordezko meta-etiketak \\
\hline$\alpha=\beta$ & $\begin{array}{l}\alpha \text { eta } \beta \text { bat datoz, hots kokagune bera adierazten dute (eta katego- } \\
\text { ria bereko itemak badira, orduan kontzeptu identifikagarriak ere ba- } \\
\text { dira) }\end{array}$ \\
\hline$\alpha \neq \beta$ & $\alpha$ eta $\beta$ desberdinak dira \\
\hline$\alpha><\beta$ & $\alpha$ eta $\beta$ elkarrengandik aldenduta daude \\
\hline$\alpha-\beta$ & ez da zehazten $\alpha$ eta $\beta$ aldenduta dauden, desberdinak izanik, ala ez \\
\hline$(\alpha-) \beta-\gamma$ & $={ }_{\text {def }}(\alpha-\beta) \wedge(\beta-\gamma)$ \\
\hline
\end{tabular}


Zenbait irudikatze grafiko erabil daitezke 1. taulako balio desberdinetako gertaerak irudikatzeko. 3. taulan halako irudikatzeen osagarriak ikus daitezke:

3. taula. Mota desberdineko gertaerak grafikoki irudikatzeko osagaiak.

\begin{tabular}{c|l}
\hline$\otimes$ & Funtsezko muga \\
\hline 1 & Denbora hutseko muga \\
\hline$\times$ & $\begin{array}{l}\text { Aspektu ikuspegiak azpimarra dezakeen muga ez-funtsezkoa, aspektu kon- } \\
\text { tuetarako intereseko muga }\end{array}$ \\
\hline---- & Garapen edo iraupena \\
\hline
\end{tabular}

2. irudian emaitzak ikus daitezke ([ $\pm \mathrm{dyn}]$ balioei erreparatu gabe):

\begin{tabular}{|l|c|}
\hline$[+$ tf, + mom $]$ & $\otimes$ \\
\hline$[+$ tf, - mom $]$ & $------\otimes$ \\
\hline$[+$ ti $]$ & $\otimes-------\mid$ \\
\hline$[-t]$ & $x-------\mid$ edo $|-------|$ \\
\hline
\end{tabular}

2. irudia. Mota desberdineko gertaeren irudikatze grafikoa.

Bi dira bideak $[+\mathrm{t}]$ baliotik $[-\mathrm{t}]$ baliora igarotzeko: serializatzea (serialization, gertaera bakar baten zenbatezko berrinterpretatze bat), eta homogeneizatzea (mugaren ezabaketa). Alderantzizko balio-aldaketarako bide nagusia mugatzea (limitation) da. 4. taulan definizioak ikus daitezke.

4. taula. Aldakuntzazkotasun-balioa aldatzeko prozesuak atzemateko tasunak.

\begin{tabular}{c|l}
\hline$[ \pm$ ser $]$ & gertaera sorta batean sartzen den / ez den adierazpena \\
\hline$[ \pm$ hom $]$ & gertaeraren muga erauzi dela / ez dela adierazteko tasuna \\
\hline$[ \pm \mathrm{lim}]$ & gertaerari funtsezko muga bat ezarri zaiola / ez zaiola adierazteko tasuna \\
\hline
\end{tabular}


Eta adibideak (Ikusi 5. taula):

5. taula. Halakoen adibideak.

\begin{tabular}{lll}
\hline Esnatu $[+\mathrm{tf}]$ & $\Rightarrow$ egunero esnatu $[+\mathrm{tf}]+[+\mathrm{ser}]$ & $=[-\mathrm{t}]$ \\
\hline Etorri $[+\mathrm{tf}]$ & $\Rightarrow$ honantz etorri $[+\mathrm{tf}]+[+\mathrm{hom}]$ & $=[-\mathrm{t}]$ \\
\hline Ibili $[-\mathrm{t}]$ & $\Rightarrow$ etxeraino ibili $[-\mathrm{t}]+[+\mathrm{lim}]$ & $=[+\mathrm{tf}]$ \\
\hline
\end{tabular}

Aspektuak ikuspegi bat edo beste ezartzen dio gertaeraren edukiari. Ikuspegiok hiru dimentsiori dagozkio: gertaera ikustearena bere mugen barruan (edo ez, \pm INTRA), bere intereseko muga igaro ondoren (edo ez, \pm POST) edo mugaren erdiespenean bertan (edo ez, \pm AD). Hiru aspektuoperatzaileok behar dira euskal aditzaren aspektua azaltzeko. Hona hemen balio positiboen irudikatze grafiko bana ('^' ikuspegia dagoen lekuan koka daiteke edo haren inguruko puntuen eremuan) (3. irudia):

\begin{tabular}{|c|c|c|c|}
\hline & + POST $^{1}$ & +INTRA & $+\mathbf{A D}$ \\
\hline$[+\mathrm{tf}]$ & $\begin{array}{r}(\mid-------) \otimes \\
\wedge \ldots .\end{array}$ & $\begin{array}{c}\mid-------\otimes{ }^{2} \\
\ldots \ldots \ldots \ldots \ldots \ldots .\end{array}$ & $\begin{array}{c}(\mid-------) \otimes{ }^{34} \\
\wedge\end{array}$ \\
\hline$[+\mathbf{t i}]$ & $\begin{array}{l}\otimes-------\mid \\
\quad \wedge \ldots \ldots \ldots \ldots \ldots \ldots \ldots \ldots \ldots \ldots \ldots \ldots \ldots \ldots\end{array}$ & $\begin{array}{c}\otimes------\left.\right|^{5} \\
\ldots \ldots \ldots \ldots \ldots \ldots\end{array}$ & $\stackrel{\wedge}{\wedge}^{\otimes------\left.\right|^{67}}$ \\
\hline$[-\mathrm{t}]$ & $\begin{array}{l}x-------\mid \\
\wedge \ldots \ldots \ldots \ldots \ldots \ldots \ldots \ldots\end{array}$ & $\begin{array}{c}|-------|^{8} \\
\ldots \ldots \ldots \ldots \ldots \ldots\end{array}$ & [Konbinaezinak] \\
\hline
\end{tabular}

3. irudia. +POST, +INTRA eta +AD balioen irudikatze grafikoak.

1 Jatorriz, -tu + aditz laguntzailea egitura +POST baliokoa zen, baina euskal aditz-sistemaren garapen diakronikoan, +INTRA balioa iraganeko adizkietara ere hedatu zenean, + POST balioa, fokuratzea galdurik, -INTRA gisa berrinterpretatu zen, \pm INTRA oposizioaren barruan.

${ }^{2}$ Esaterako: etxera dator / zetorren. Taulotako ondoko oharretan dagozkien adibideak agertuko dira.

3 Zatoz berehala!

4 XVI. mendeko aoristo zaharrak ere balio hau zuen: etxera etor zedin ( $\approx$ etorri zen).

5 Aurrera noa / nindoan. Ikusten dut / nuen.

6 Ikus nazazu!

7 Aoristo zaharrean: ibil zedin; aurrera joan gintezen...

8 Etxean nago / nengoen. Kaletik zabiltza / zenbiltzan. 
Balio negatiboekin analizatu ez den osotasun gisa ikustatzen da gertaera. Honelako zerbait: $\mid-\otimes, \otimes-I$, eta $x-\mid$ edo $|-|$. Ondorioz (ikusi 4. irudia):

\begin{tabular}{|c|c|c|c|}
\hline & -POST & -INTRA & $-A D$ \\
\hline$[+\mathrm{tf}]$ & $\wedge \quad(\mid-) \otimes$ & $(\mid-) \otimes \quad \ldots \wedge \quad 9$ & $\begin{array}{c}\mid-\otimes \\
\wedge \ldots \ldots \ldots\end{array}$ \\
\hline$[+\mathrm{ti}]$ & ${ }^{4} \ldots \ldots \ldots . .$. & 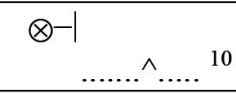 & \begin{tabular}{|c|}
$\otimes-1$ \\
$\ldots \ldots \ldots \ldots . . . . \ldots \ldots$ \\
\end{tabular} \\
\hline$[-t]$ & ${ }^{\wedge} \ldots \ldots \ldots$ & ${ }^{|-|} \ldots \ldots . \ldots . . .{ }^{11}$ & 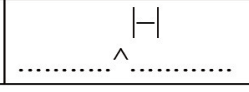 \\
\hline
\end{tabular}

4. irudia. -POST, -INTRA eta -AD balioen irudikatze grafikoak.

+INTRA eta +POST balioekin fokuratze-eskala bat bereizi behar da aspektu-operatzaileen aplikazioan: fokuratze handiena (fokuratze txikiena ez bezala) ikuspegiaren kokagunera mugatzen da, gertaera osoa edo haren zati bat kanpoan lagaz. Bereizketa horiek adierazteko honelako markak erabil daitezke operatzaileari itsatsita goiindize gisa (ikusi 6. taula):

6. taula. +POST eta +INTRA balioen fokuratze-eskala.

\begin{tabular}{c|l}
\hline F & ikuspegi fokuratuaren adierazpena \\
\hline NF & ikuspegi ez fokuratuaren adierazpena \\
\hline LF & gutxi fokuraturiko ikuspegiaren adierazpena \\
\hline HF & oso fokuraturiko ikuspegiaren adierazpena ${ }^{12}$ \\
\hline
\end{tabular}

Honekin guztiarekin zehatz daiteke Ô-ren eta gertaeraren arteko erlazioa. Aurreko oin-oharretan ikusi dira zenbait adibide. 5. irudian beste batzuk ikus daitezke:

9 Etxera etorri da / zen.

10 Entzun dugu / genuen.

11 Ibili naiz / nintzen.

12 Grafikoki fokuratze handiko ikuspuntuaren eremu posiblea hertsiagoa da, '..^..' ohiko '............' eskemaren ordez. +INTRA ${ }^{\mathrm{HF}}$ egitura tipikoak [+dyn] baliokoak dira, euskal ari izan perifrasiak esaterako. +POSTHF egituren artean kokatu behar dira erresultatiboak, euskarazko -tua / turik / tuta + aditz laguntzailea egiturak legez. 
Euskararen tempus-aspektu-modu sistemaren trataera formala

\begin{tabular}{|c|c|c|}
\hline Mugitzen ari naiz / nintzen & + INTRA $^{\mathrm{HF}} \times[+$ dyn $] \times[-\mathrm{t}]$ & $|-------|$ \\
\hline Entzuten ari gara / ginen & $" \times[+\mathrm{ti}]$ & $\otimes-------\mid$ \\
\hline Bukatzen ari da / zen & $" \times[+\mathrm{tf}]$ & $\begin{array}{c}\mid-------\otimes \\
\text {.ồ.. }\end{array}$ \\
\hline Kaletik mugitzen zara / zinen & + INTRA $^{\mathrm{LF}} \times[-\mathrm{t}]$ & $|-------|$ \\
\hline Entzuten dut / nuen & $" \times[+\mathrm{ti}]$ & $\otimes-------\mid$ \\
\hline Berehala bukatzen dut & $" \times[+\mathrm{tf}]$ & $\begin{array}{l}\mid-------\otimes \\
\text {.................. }\end{array}$ \\
\hline Mendietatik ibiltzen naiz / nintzen & + INTRA $^{\mathrm{LF}} \times[-\mathrm{t}]+[+\mathrm{ser}]$ & $|--+\ldots+x--+\ldots+--|$ \\
\hline Aurrera joaten gara / ginen & $\times[+\mathrm{ti}]+\quad "$ & $|--+\ldots+\otimes--|+\ldots+--\mid$ \\
\hline Etxera etortzen da / zen & $" \quad \times[+\mathrm{tf}]+"$ & $\begin{array}{l}|--+\ldots+|--\otimes+\ldots+--\mid \\
\ldots \ldots \ldots \ldots \ldots . . . . . . . \ldots \ldots \ldots \ldots . . .\end{array}$ \\
\hline Ibilia naiz / nintzen & $+\mathrm{POST}^{\mathrm{HF}} \times[-\mathrm{t}]$ & $x------\mid$ \\
\hline Joanik gara / ginen & $" \times[+\mathrm{ti}]$ & $\otimes------1$ \\
\hline Etxera etorria da / zen & $" \times[+\mathrm{tf}]$ & $\begin{array}{r}\mid------\otimes \\
\text {..ô... }\end{array}$ \\
\hline
\end{tabular}

5. irudia. Irudikatze grafikoen adibideak (I).

Oraingoz, baina, gutxi esan da Ô-ren (ikuspegiaren kokagunea den orientazio puntuaren) eta bestelako orientazio puntuen arteko harremanaz. Ondoko atalaren jarduna izango da hori.

\section{ORIENTAZIO-PUNTUEN ALDENTZEA DIMENTSIO MODALEAN ETA DENBORAZKOAN}

Gertaerak era eraginkorrean lokalizatu ahal dira 1. irudiko espazio semantikoan. Izan ere, zatikako ordena hertsi bat ezar daiteke orientazio-puntuen artean eta, ondorioz, erlazio zehatz bat egongo da Ô-ren eta $\mathrm{O}^{1 \mathrm{~S}}$-ren artean. $\mathrm{O}^{1 \mathrm{~S}}$-ez besteko $\mathrm{O}$ guztiak aldendu egiten dira hartatik bide batean edo bestean, moduzko dimentsioan zehar, denborazko dimentsioan zehar, edo bietan zehar (ikusi 6. irudia).

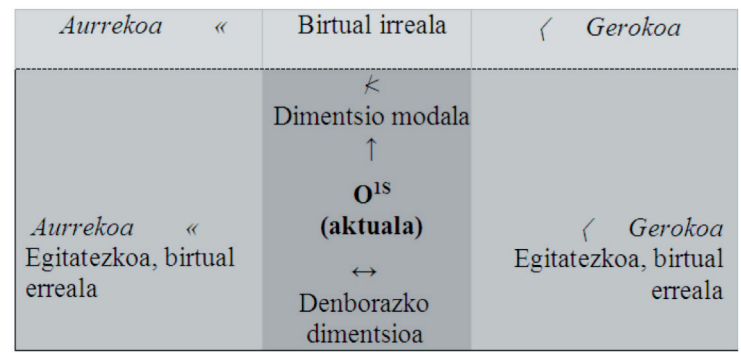

6. irudia. Lehen orientazio-puntutiko denborazko aldentzea eta aldentze modala. 
Moduari / modalitateari dagokionez gertaerak aurkez daitezke erreal edo irreal modura, eta hori [ \pm irrealis] tasun batez atzeman dezakegu. [+irrealis] balioarekin batera gertaeraren gaineko ikuspegia (eta gertaera bera) urrundu egingo da jatorrizko $\mathrm{O}^{1 \mathrm{~S}}$-tik. Grafikoki desplazamendu hori bertikalki adieraziko dugu, ' $\nless$ ' zeinua tartekatuz. Denborazko desplazamenduak ' $<$ ' erlazioari dagozkio eta horizontalean adieraziko dira. Hala ere, erlazio horretan $\mathrm{O}^{1 \mathrm{~S}}$-tik hurbilago dago abiapuntua, eta hori adierazteko $\mathrm{O}^{1 \mathrm{~S}}$-tik iraganera (ezkerretara) '" erabiliko da eta gerora (eskumatara) '/' zeinua. Aldentze biotatik zein den kasukoa argi ez dagoenean, azken zeinu hori eskumatara eta gorago agertuko da. Aldentze biak indarrean daudenean berdin egingo da ' $\nless$ ' zeinuarekin.

Denborazko aldentze hutsaren adibide ona eskaintzen dute egitura gainkonposatuek (Ikusi 7. irudia):

\begin{tabular}{|c|c|c|}
\hline- INTRA $\left(+\right.$ POST $\left.^{\mathrm{HF}}\right) \times[-\mathrm{t}]$ & Ibilia izan naiz & $x-------1$ \\
\hline$" \times[+\mathrm{ti}]$ & Joanik izan gara & $\otimes-------\mid$ \\
\hline$" \times[+\mathrm{tf}]$ & Etxera etorria izan da & $\mid-------\otimes$ \\
\hline & & $. . \hat{O}^{2} . . \ll \ldots \mathbf{O}^{1 S}$ \\
\hline -INTRA $\left(+\right.$ POST $\left.^{\text {LF }}\right) \times[-\mathrm{t}]$ & Ibili izan naiz & $x-------\mid$ \\
\hline$" \times[+\mathrm{ti}]$ & Joan izan gara & $\otimes-------\mid$ \\
\hline$" \times[+\mathrm{tf}]$ & Etxera etorri izan da & $\begin{array}{l}\mid-------\otimes \\
\quad \ldots \ldots \ldots \ldots \hat{O}^{2} \ldots \ldots \ldots \ll \ldots \mathbf{O}^{1 \mathrm{~S}} \ldots . . . .\end{array}$ \\
\hline
\end{tabular}

7. irudia. Irudikatze grafikoen adibideak (II): egitura gainkonposatuak.

Bai moduzko aldentzearen erlazioak, eta bai denborazko aldentzearen erlazioak zatikako ordena hertsi bat ezartzen dute espazio semantikoaren itemen artean, biak izanik irreflexiboak eta iragankorrak (eta, ondorioz, asimetrikoak). 7. taulan definizio zehatzak ikus daitezke.

Taulan ageri denez, bereiz daitezke gerokotasuna (erreala zein irreala), gertagarritasuna (gerokotasun irreala) eta ondorengotasuna (gerokotasun erreala).

[+irrealis] balioa dakarten faktoreen artean ondokoak daude: (errotiko) ahalezkotasuna [2] (altxa dezaket), asmozkotasuna (subjuntiboko zenbait perpaus osagarritan eta aginte-adizkietan aurki daitekeena: altxa dezadan!, altxa dezadan espero dute). Hara daude era berean Mervyn R. Hareren $[3,4,5,6]$ lanak oinarri, hitzemate neustikoaren aldaera gisa bereizi ditudanetako bi [7, 8] - haren baretzea (altxatzen duket) eta sub iudice jartzea (altxatzen badut, ainu altxatu(ren)!) -.${ }^{13}$ Hareri berari jarraituz,

13 Aldaera biok kontrajartzen zaizkio berezko hitzemate neustiko (adierazitako gertaeraren asetzearekiko konpromiso) neutroari (altxatzen dut). 
7. taula. Moduzko eta denborazko desplazamendu-erlazioen definizioak eta zenbait postulatu.

\begin{tabular}{|c|c|}
\hline$\beta<\alpha$ & $\begin{array}{l}\text { Denborazko ordena honetan aurkezten dira } \beta \text { eta } \alpha \\
\text { (dena delako) itemak (gertaerak, gertaera-faseak, orien- } \\
\text { tazio-puntuak...): } \beta \text { lehenago, } \alpha \text { ondoren }\end{array}$ \\
\hline$\beta \ngtr \alpha($ edo $\alpha /<\beta):$ & $\begin{array}{l}\beta \text {-ren } \alpha \text {-tiko aldentzea ez dagokio denboraren lerroari, } \\
\text { dimentsio modal bati baizik }\end{array}$ \\
\hline$\alpha^{\mathrm{n}}$ & $\begin{array}{l}\alpha \text { itema bere kategoriako } n \text {-garrena da, } n \text { goiindizea } \\
\text { zenbaki bat izanik. }\end{array}$ \\
\hline$\alpha^{\mathrm{S}}$ & $\alpha$ itema $S$ hizketa-gune bat da \\
\hline$\hat{\alpha}$ & aspektu ikuspegia $\alpha$ itemean dago kokaturik \\
\hline$(\stackrel{(}{\alpha})$ & $\begin{array}{l}\alpha \text { itemean ikuspegia kokaturik dagoenean zein ez da- } \\
\text { goenean aplikagarria den notazioa }\end{array}$ \\
\hline $\mathrm{O}^{\mathrm{nS}}$ & $={ }_{\text {def }} \mathrm{O}^{\mathrm{n}} \wedge \mathrm{O}^{\mathrm{S}}:\left(\mathrm{O}^{\mathrm{n}}=\mathrm{O}^{\mathrm{S}}\right)$ \\
\hline [+irrealis] & $={ }_{\text {def }}\left(\mathrm{G} \ngtr \mathrm{O}^{\mathrm{n}}\right)$ \\
\hline [+irrealis $]$ & $\begin{array}{l}={ }_{\text {def }}\left(\left(\hat{O}^{n+m}(-\ldots)\left(-\mathrm{O}^{\mathrm{n}+\mathrm{k}}\right) \ngtr \mathrm{O}^{\mathrm{n}}\right)\right) \vee\left(\left(\hat{\mathrm{O}}^{\mathrm{n}+\mathrm{m}} \ngtr(\ldots-)\right.\right. \\
\left.\left.\left(\mathrm{O}^{\mathrm{n}+\mathrm{k}}-\right) \mathrm{O}^{\mathrm{n}}\right)\right) \\
(\text { Definizio esplizitua. })\end{array}$ \\
\hline$[+$ irrealis $]$ & $={ }_{\text {def }}\left(\hat{O}^{n+m} \ngtr \mathrm{O}^{\mathrm{n}}\right)$ (Definizio laburtua.) \\
\hline $\operatorname{AURREKOA}(\beta, \alpha)$ & $==_{\text {def }}(\beta<\alpha) \wedge\left((\beta \neq O) \vee\left(\stackrel{(}{\beta}^{n+m} \wedge \alpha^{n}\right)\right)$ \\
\hline $\operatorname{GEROKOA}(\alpha, \beta)$ & $==_{\text {def }}(\beta<\alpha) \wedge\left((\alpha \neq O) \vee\left(\hat{\alpha}^{()_{n+m}} \wedge \beta^{n}\right)\right)$ \\
\hline$\beta \ll \alpha$ & $={ }_{\text {def }} \operatorname{AURREKOA}(\beta, \alpha)$ \\
\hline$\beta<^{\alpha}$ & $\begin{array}{l}\alpha \text { gerokoagoa da } \beta \text { baino, eta zehaztu gabe gelditzen da } \\
\text { aldi berean } \alpha \text { modalki ere aldentzen den } \beta \text {-tik }\end{array}$ \\
\hline$\beta\left\langle^{\alpha}\right.$ & $={ }_{\text {def }} \operatorname{GEROKOA~}(\alpha, \beta)$ \\
\hline $\operatorname{GERTAGARRIA}(\alpha, \beta)$ & $={ }_{\text {def }} \operatorname{GEROKOA}(\alpha, \beta) \wedge[+$ irrealis $]$ \\
\hline$\beta^{1<\alpha}$ & $={ }_{\text {def }} \operatorname{GERTAGARRIA~}(\alpha, \beta)$ \\
\hline ONDORENGOA $(\alpha, \beta)$ & $==_{\text {def }} \operatorname{GEROKOA}(\alpha, \beta) \wedge[$-irrealis $]$ \\
\hline$\beta<\alpha$ & $==_{\text {def }}$ ONDORENGOA $(\alpha, \beta)$ \\
\hline Irreflexibotasun postulatuak & $\begin{array}{l}\neg(\alpha<\alpha) \\
\neg(\alpha \ngtr \alpha) \\
\end{array}$ \\
\hline Iragankortasun postulatuak & $\begin{array}{l}((\alpha<\beta) \wedge(\beta<\gamma)) \rightarrow(\alpha<\gamma) \\
((\alpha \ngtr \beta) \wedge(\beta \ngtr \gamma)) \rightarrow(\alpha \ngtr \gamma)\end{array}$ \\
\hline
\end{tabular}


aginte-adizkiak ez dira deskribatzaileak, ezarleak baizik (hizketa-egintzen teorikoek ondo erakutsi dutenez [9], geroko gertaera bati so egiten diote) (ikusi 8. taula).

8. taula. [+irrealis] balioaren zenbait eragile.

\begin{tabular}{|c|c|}
\hline [ \pm ahal $]$ & $\begin{array}{l}\text { gertaerak errotiko ahalezkotzat aurkeztearen / ez aurkeztearen } \\
\text { adierazpena }\end{array}$ \\
\hline [ \pm asmozkoa] & $\begin{array}{l}\text { gertaerak asmoaren eremukoak izatearen / ez izatearen adieraz- } \\
\text { pena }\end{array}$ \\
\hline \pm BARETUA & $\begin{array}{l}\text { emandako hitzemate neustiko baretuaren / baretu gabearen adie- } \\
\text { razpena }\end{array}$ \\
\hline $\pm S U B$ IUDICE & $\begin{array}{l}\text { (aditz-esaera nominalizatu batez adierazitako) «eduki frastikoa- } \\
\text { ren» asetzearekiko hitzemate neustikoa gorde (edo ez) eta iritzi- } \\
\text { pean jartzearen (edo ez jartzearen) adierazpena }\end{array}$ \\
\hline \multirow{4}{*}{ Postulatuak } & {$[+$ ahal $] \rightarrow[+$ irrealis $]$} \\
\hline & {$[+$ asmozkoa $] \rightarrow[+$ irrealis $]$} \\
\hline & $(+$ BARETUA $\vee+$ SUB IUDICE $) \rightarrow[+$ irrealis $]$ \\
\hline & $\begin{array}{l}{[+ \text { irrealis }] \leftrightarrow(+\mathrm{BARETUA} \vee+\text { SUB IUDICE } \vee[+ \text { asmoz- }} \\
\text { koa }] \vee[- \text { deskr }] \vee[+ \text { ahal }])\end{array}$ \\
\hline [+deskr] & $\begin{array}{l}\text { Ilokuzio-indarraren lehen markatzaileek linguistikoki kodeturiko } \\
\text { «eduki frastikoa munduarekiko» egokitzapen norabidea }\end{array}$ \\
\hline [-deskr] & $\begin{array}{l}\text { Ilokuzio-indarraren lehen markatzaileek linguistikoki kodeturiko } \\
\text { «mundua eduki frastikoarekiko» egokitzapen norabidea }\end{array}$ \\
\hline [HORTATIBOA] & $\begin{array}{l}\text { hizketa-egintza zuzentzaileak linguistikoki kodetzen dituen aditz- } \\
\text { modua }\end{array}$ \\
\hline \multirow{3}{*}{ Postulatuak } & {$[-$ deskr $] \rightarrow[+$ asmozkoa $]$} \\
\hline & {$[-$ deskr $] \rightarrow \operatorname{GEROKOA}\left(\hat{\mathrm{O}}^{\mathrm{n}+\mathrm{m}}, \mathrm{O}^{1 \mathrm{~S}}\right)$} \\
\hline & {$[-$ deskr $] \leftrightarrow[$ HORTATIBOA $]$} \\
\hline
\end{tabular}

Johansonek proposaturiko beste operatzaile bat, +PRO (prospective) aurrikusleak (euskaraz -(tu)ko motako partizipioen eta -(te)ke hizkidun adizkiez adieraziak), gertaeraren gaineko ikuspegia proiektatzen du geroan edo / eta +BARETUA balioa ezartzen du (ziurgabetasun kutsua inplikatuz (ikusi 9. taula): 
9. taula. Aurrikuslearen definizioa eta balioak.

\begin{tabular}{c|l}
\hline \pm PRO & $\begin{array}{l}\text { gertaeraren gaineko ikuspegia aurreikusia (prospective) dela / ez dela } \\
\text { adierazten duen operatzailea }\end{array}$ \\
\hline Postulatua & $+\mathrm{PRO} \rightarrow\left(\right.$ GEROKOA $\left.\left(\hat{\mathrm{O}}^{\mathrm{n}+\mathrm{m}}, \mathrm{O}^{\mathrm{n}}\right) \vee+\mathrm{BARETUA}\right)$ \\
\hline$< \pm($ te $) \mathrm{ke}>$ & $-(t e) k e$ hizkiaren agerpenaren / agerpen ezaren adierazpena \\
\hline$< \pm(t u) k o>$ & $\begin{array}{l}\text { adizki jokatuan }-(t u) k o \text { motako partizipio bat egotearen / ez egotearen } \\
\text { adierazpena }\end{array}$ \\
\hline Postulatua & $+\mathrm{PRO} \leftrightarrow(<+(t u) k o>\vee<+(t e) k e>)$ \\
\hline
\end{tabular}

8., 9., eta 10. irudietan zenbait irudikatze grafiko ikus daitezke:

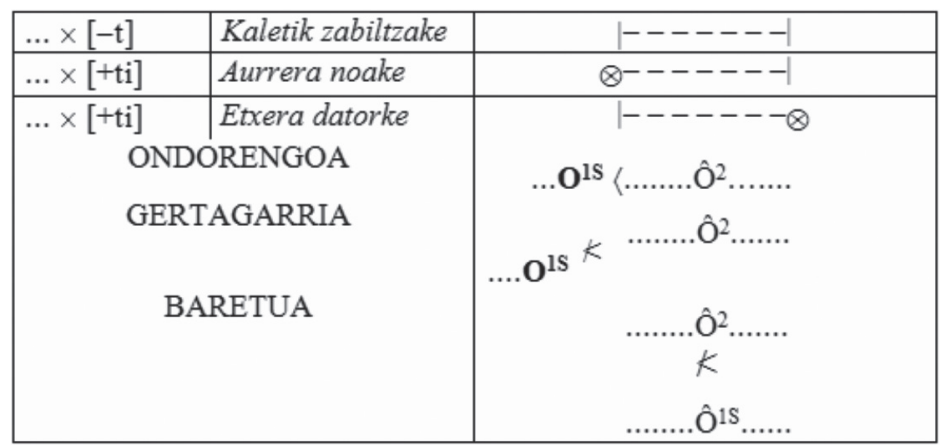

8. irudia. Irudikatze grafikoen adibideak (III): +PRO (+INTRA $\left.{ }^{\mathrm{LF}}\right)$.

\begin{tabular}{|c|c|c|}
\hline$\ldots \times[-\mathrm{t}]$ & Ibiliko naiz & $x-1$ \\
\hline$\ldots \times[+\mathrm{ti}]$ & Aurrera joango gara & $\otimes-1$ \\
\hline$\ldots \times[+\mathrm{ti}]$ & Etxera etorriko da & $\mid-\otimes$ \\
\hline & ORENGOA & $\mathrm{O}^{1 \mathrm{~S}} / \hat{O}^{2}$ \\
\hline & TAGARRIA & $\hat{\mathrm{O}}^{2}$ \\
\hline \multirow{3}{*}{\multicolumn{2}{|c|}{ BARETUA }} & $\ldots \mathbf{O}^{1 \mathrm{~S}^{k}}$ \\
\hline & & $\ldots \ldots . . \hat{O}^{2} \ldots \ldots$ \\
\hline & & $\ldots . . . \mathrm{O}^{1 \mathrm{~S}} \ldots . .$. \\
\hline
\end{tabular}

9. irudia. Irudikatze grafikoen adibideak (IV): +PRO (-POST). 


\begin{tabular}{|l|l|r|}
\hline$\ldots \times[-\mathrm{t}]$ & Ibilia naizateke / izango naiz & $\times------\mid$ \\
\hline$\ldots \times[+\mathrm{ti}]$ & Joanik garateke / izango gara & $\otimes^{-------\mid}$ \\
\hline$\ldots \times[+\mathrm{ti}]$ & $\begin{array}{l}\text { Etxera etorria dateke / izango da } \\
\text { ONDORENGOA }\end{array}$ & $\begin{array}{l}-----\otimes \\
\text { ONO......... }^{1 \mathrm{~S}}\left\langle. . \mathrm{O}^{2} . .\right.\end{array}$ \\
\hline
\end{tabular}

10. irudia. Irudikatze grafikoen adibideak $(\mathrm{V}):+\mathrm{PRO}\left(+\mathrm{POST} \mathrm{HF}^{\mathrm{HF}}\right)$, interpretazio erreala. ${ }^{14}$

Ahalerako adizkiek, beren aldetik, gertagarritasunean kokatzen dute ikuspegia (Ikusi 10. taula eta 11. irudia).

10. taula. Ahaleraren gertagarritasuna.

\begin{tabular}{c|l}
\hline $\mathrm{L}_{\mathrm{A}}$ & ahalaren zein ezinaren lokalizatze-puntua (Ô-ren batekin erlazionatua) \\
\hline Postulatua & {$[+$ ahal $] \rightarrow\left(\mathrm{L}_{\mathrm{A}}{ }^{\mathrm{M})}\right.$} \\
\hline
\end{tabular}

\begin{tabular}{|c|c|}
\hline Egin ahal dut & $\begin{array}{c}\mid------\otimes \\
k \\
\ldots . \hat{\mathbf{O}}^{1 \mathrm{~S}}=\mathrm{L}_{\mathrm{A}} \ldots .\end{array}$ \\
\hline Egin (ahal) dezaket & $\begin{array}{c}\mid------\otimes \\
K^{\mathrm{O}^{2}} \\
\ldots . \mathbf{O}^{1 \mathrm{~S}}=\mathrm{L}_{\mathrm{A}} \ldots .\end{array}$ \\
\hline Egiten (ahal) dut & 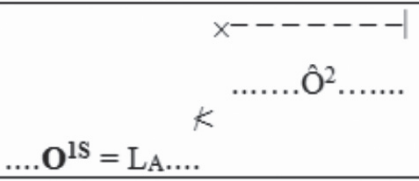 \\
\hline
\end{tabular}

11. irudia. Irudikatze grafikoen adibideak (VI): ahaleraren gertagarritasuna.

Irrealtasuna [+ahal] balioari dagokio; gerokotasuna hainbat bidetatik lor daiteke, aldaera diakroniko eta diatopikoek erakusten duten bezala.

14 Irrealak erraz ondoriozta daitezke, baita +PRO (+POST ${ }^{\mathrm{LF}}$ ) baliokotzat jo daitezkeen ibili naizateke egiturakoak ere. 
Bide haietako bat da *edin eta *ezan (bizkaieraz egin) aditzen formak erabiltzea (ahal eta ezin partikulekin konbinatuz edo ez), eskuarki +PRO balioko -(te)ke hizkiaz horniturik. Izan ere, *edin eta *ezan aditzen esanahi lexikoan [+tf, +mom] balioak daude. Horregatik ezin batera daitezke +INTRA ikuspegiarekin $\left(\mathrm{O}^{(1) \mathrm{S}}\right.$-ri berezkoa zaionarekin); +AD balioa, ordea, ezin egokiagoa zaie. Baina $+\mathrm{AD}$ aspektu ikuspegia unibertsalki bateraezina da $\mathrm{O}^{(1) S}$-rekin (Johanson 2000, § 9.2). Ondorioz, aditzok defektiboak dira: orainaldiko adizki soilak aginte-adizkiak izan behar dira (hadi, ezazu...); bestelakoek hizkiren bat edo beste behar dute (ba-, ai(t)-, -(te)ke, $-n$, -la) $\mathrm{O}^{(1) \mathrm{S}}$-tiko aldentze horrekin semantikoki bat etortzeko. Horietako -(te)ke hizkiak soilik ez dio gehitzen (+PRO balioaz) bestelako esanahiren bat adizkiari (Ikusi 11. taula).

11. taula. +AD operatzailearen zenbait inplikazio.

\begin{tabular}{c|l}
\hline$< \pm *$ EDIN $>$ & adizkia *EDIN aditzekoa izatearen / ez izatearen adierazpena \\
\hline$< \pm *$ EZAN $($ EGIN $)>$ & $\begin{array}{l}\text { adizkia *EZAN }(\text { EGIN }) \text { aditzekoa izatearen } / \text { ez izatearen } \\
\text { adierazpena }\end{array}$ \\
\hline$< \pm *$ IRON $>$ & adizkia *IRON aditzekoa izatearen $/$ ez izatearen adierazpena \\
\hline \multirow{2}{*}{ Postulatuak } & $(<+*$ EDIN $>\vee<+* E Z A N($ EGIN $)>\vee<+* I R O N>) \rightarrow+A D$ \\
\cline { 2 - 2 } & $\left(+\mathrm{AD} \wedge\left(\mathrm{O}^{\mathrm{nS}}-\hat{\mathrm{O}}^{\mathrm{n}+1}\right)\right) \rightarrow\left(\mathrm{O}^{\mathrm{nS}}\left\langle\hat{\mathrm{O}}^{\mathrm{n}+1}\right)\right.$ \\
\hline
\end{tabular}

Proiekzio hori ezin hobeto datorkie aginte-adizkiei. Euskaraz $+\mathrm{AD}$ baliokoak dira denak (ikusi 12. taula eta 12. irudia).

12. taula. Aginte-adizkien $+\mathrm{AD}$ balioa.

\begin{tabular}{l|l}
\hline Postulatua & {$[-$ deskr $] \rightarrow+$ AD } \\
\hline
\end{tabular}

\begin{tabular}{|c|l|c|}
\hline$+\mathrm{AD} \times *[-\mathrm{t}]>[+\mathrm{ti}]$ & Ibil hadil / Habill / Hago! & $\otimes^{-------\mid}$ \\
\hline$" \times[+\mathrm{ti}]$ & Entzun ezazu! / Zoaz aurrera! & $\otimes^{-------\mid}$ \\
\hline$" \times[+\mathrm{tf}]$ & Etor zaitezte / Zatozte etxera! & $\mid------\otimes$ \\
& & $\mathbf{0}^{1 \mathrm{~s}} \mathrm{O}^{2}$ \\
\hline
\end{tabular}

12. irudia. Irudikatze grafikoen adibideak (VII): zenbait aginte-adizki. 
+INTRA operatzaileak ere proiekta dezake ikuspegia geroan, baldin ageria bada, testuinguruagatik, adierazitakoa ez dela oraingoz gertatzen ari (ikusi 13. taula eta 13. irudia):

13. taula. Ô geroan proiektatzeko faktoreak.

\begin{tabular}{c|l}
\hline Postulatua & GEROKOA $\left(\hat{O}^{\mathrm{n}+\mathrm{m}}, \mathrm{O}^{\mathrm{n}}\right) \rightarrow\left(+\mathrm{PRO} \vee+\mathrm{AD} \vee\left(+\mathrm{INTRA} \wedge\left(\mathrm{G} \cap \mathrm{O}^{\mathrm{M}}=\varnothing\right)\right)\right.$ \\
\hline $\mathrm{O}^{\mathrm{M}}$ & $\begin{array}{l}\text { gai hurbil eta urrunaren bidez morfologikoki adierazitako orientazio- } \\
\text { puntuak (ikus aurrerago) }\end{array}$ \\
\hline
\end{tabular}

\begin{tabular}{|l|ll|}
\hline Hori... etxean nagoenean & & $|-------|$ \\
& ols $\left\langle\quad \ldots . . . . \mathrm{O}^{2} \ldots . . .\right.$. \\
\hline
\end{tabular}

13. irudia. Irudikatze grafikoen adibideak (VIII): +INTRA balioa eta Ô-ren proiekzioa geroan.

Baina badago oso bestelako bide bat ikuspegia $\mathrm{O}^{1 \mathrm{~S}}$-tik aldentzen duena eta adizki trinko eta laguntzaileen gai urruna eta hurbilari dagokiona. Horren bidez morfologikoki markatzen dira hiru orientazio-puntu nagusi, hizketa-gunearen ingurukoa edo oraingunekoa $\left(\mathrm{O}^{1 \mathrm{~S}}\right)$, iraganaldikoa $\left(\mathrm{O}^{2 \mathrm{P}}\right)$ eta alegigunekoa $\left(\mathrm{O}^{2 \mathrm{~V}}\right)$ (ikusi 14. irudia).

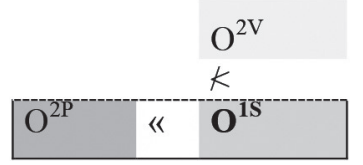

14. irudia. Morfologikoki markaturiko hiru orientazio-guneak. 
15. eta 16. irudietan zenbait adibide ikus daitezke:

\begin{tabular}{|c|c|c|}
\hline$+\mathrm{AD} \times *[-\mathrm{t}]>[+\mathrm{ti}]$ & $\begin{array}{l}\text { Ibil bedil/ Bebil! / Bego! } \\
\text { Ailedi ibill/ Ibil baledi! }\end{array}$ & Q------- \\
\hline$" \times[+\mathrm{ti}]$ & $\begin{array}{l}\text { Entzun bezate! / Bihoa aurrera! } \\
\text { Ailezate entzun! / Entzun balezate! }\end{array}$ & $Q^{-------1}$ \\
\hline$" \times[+\mathrm{tf}]$ & $\begin{array}{l}\text { Etor bitez / Betoz etxera! } \\
\text { Ailitez etxera jin! / Etxera etor } \\
\text { balitez! } \\
\text { Aikintez sar! / Sar bagintez! }\end{array}$ & 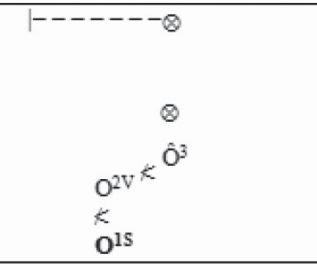 \\
\hline- INTRA $\times[-\mathrm{t}]$ & Ailitz ibili!// Ibili balitz! & $|-|$ \\
\hline$" \times[+\mathrm{ti}]$ & $\begin{array}{l}\text { Ailute entzun! / Entzun balute! / } \\
\text { Ailitz aurrera joan!/ Aurrera joan } \\
\text { balitz! }\end{array}$ & $\theta-1$ \\
\hline$" \times[+\mathrm{tf}]$ & $\begin{array}{l}\text { Ailira etxera jin! Etxera etorri } \\
\text { balira! } \\
\text { Aikina sartu! Sartu bagina! }\end{array}$ & $\begin{aligned} \theta & \\
\theta & \\
& \\
& \hat{O}^{3} \ldots \ldots \\
& k \\
& O^{2 \mathrm{~V}} \\
& k \\
& \mathbf{o}^{1 \mathrm{~s}}\end{aligned}$ \\
\hline+ INTRA $\times[-\mathrm{t}]$ & Ailebil!/Balebil! & $|-------|$ \\
\hline$" \quad x[+t i]$ & $\begin{array}{l}\text { Ailute entzuten!/ Entzuten balute! } \\
\text { / Ailihoa aurrera! / Aurrera } \\
\text { balihoa! }\end{array}$ & Q -------1 \\
\hline$" \quad \times[+\mathrm{tf}]$ & $\begin{array}{l}\text { Ailira etxera jiten! Etxera baletoz! } \\
\text { Aikina sartzen! Sartzen bagina! }{ }^{15}\end{array}$ & 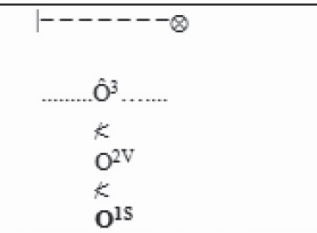 \\
\hline
\end{tabular}

15. irudia. Irudikatze grafikoen adibideak (IX): alegigunekoak.

15 Sartzekotan ez gaudenean esango lirateke honelakoak, arrazoi pragmatikoengatik inplikatuz ez dugula azken muga erdiesteko itxaropenik. 


\begin{tabular}{|c|c|c|c|}
\hline- INTRA $\times[-\mathrm{t}]$ & Ibili nintzen & $|-|$ & \\
\hline$" \times[+\mathrm{ti}]$ & Entzun genizun & $\otimes-1$ & \\
\hline \multirow[t]{2}{*}{$" \times[+\mathrm{tf}]$} & \multirow[t]{2}{*}{ Etxera etorri zen } & $1-\otimes$ & \\
\hline & &.$\hat{\mathrm{O}}^{2 \mathrm{P}}$ & $« \mathbf{O}^{1 \mathrm{~S} 16}$ \\
\hline$+\mathrm{POST}^{\mathrm{HF}} \times[-\mathrm{t}]$ & Ibilia nintzen & $x^{-------1}$ & \\
\hline$" \times[+\mathrm{ti}]$ & Aurrera joanik ginen & $\otimes-------1$ & \\
\hline \multirow[t]{2}{*}{$" \times[+\mathrm{tf}]$} & \multirow[t]{2}{*}{ Etxera etorria zen } & $\mid-------\otimes$ & \\
\hline & &.. $\mathrm{O}^{2 \mathrm{P}}$. & $\ll \mathbf{O}^{1 \mathrm{~S}}$ \\
\hline$+\mathrm{PRO}(-\mathrm{POST}) \times[-\mathrm{t}]^{17}$ & Ibiliko nintzen / nintzatekeen & $x-1$ & \\
\hline$" \times[+\mathrm{ti}]$ & Aurrera joango ginen / ginatekeen & $\otimes-1$ & \\
\hline \multirow[t]{3}{*}{$" \times[+\mathrm{tf}]$} & \multirow[t]{3}{*}{ Etxera etorriko zen / zatekeen } & \multirow{2}{*}{\multicolumn{2}{|c|}{$k^{1-\otimes . . \hat{O}^{3} \cdots}$}} \\
\hline & & & \\
\hline & & $\mathrm{O}^{2 \mathrm{P}}$ & $\ll \mathrm{O}^{1 \mathrm{~S}}$ \\
\hline
\end{tabular}

16. irudia. Irudikatze grafikoen adibideak (X): iraganaldikoak.

$< \pm$ urruna $>$ tasun morfologikoa korrelazioan jartzen da \pm FAR operatzaile johansondar batekin (jatorrizko bertsioan \pm PAST) (ikusi 14. taula):

14. taula. $\pm F A R$ operatzailea eta seinalatzen dituen eremuak.

\begin{tabular}{c|l}
\hline $\mathrm{O}^{\mathrm{M}}$ & $\begin{array}{l}\text { gai hurbil eta urrunaren bidez morfologikoki adierazitako } \\
\text { orientazio-puntuak }\left(\mathrm{O}^{1 \mathrm{~S}} \text {, eta segidan definituko diren } \mathrm{O}^{\mathrm{P}} \text { eta }\right. \\
\left.\mathrm{O}^{\mathrm{V}}\right) \text {; gertaeren gaineko ikuspegi ororen funtsezko hiru ain- } \\
\text { guratze-gune desberdin osatzen dituzte }\end{array}$ \\
\hline $\mathrm{O}^{(2) \mathrm{P}}$ & $\begin{array}{l}\text { iraganaldiaren orientazio-puntua: gai urruneko adizki baten } \\
\text { bidez adierazten da eta denborazko harreman linealean dago } \\
\text { lehen orientazio-puntuarekin;_honelaxe zehazki: } \mathrm{O}^{2} \text { « } \mathrm{O}^{1 \mathrm{~S}}\end{array}$ \\
\hline$(\hat{\mathrm{O}}-) \mathrm{O}^{(2) \mathrm{P}}$ & $\left.={ }_{\text {def }}(\hat{\mathrm{O}}-)\right) \mathrm{O}^{(2) \mathrm{M}}$ « $\mathrm{O}^{1 \mathrm{~S}}$ \\
\hline $\mathrm{O}^{(2) \mathrm{V}}$ & $\begin{array}{l}\text { alegigunearen orientazio-puntua: ai urruneko adizki baten } \\
\text { bidez adierazten da, baina ez dago denborazko harreman li- } \\
\text { nealean lehen orientazio-puntuarekin, } \mathrm{O}^{2} \ngtr \mathrm{O}^{1 \mathrm{~S}}\end{array}$ \\
\hline$(\hat{\mathrm{O}}-) \mathrm{O}^{(2) \mathrm{V}}$ & $={ }_{\text {def }}(\hat{\mathrm{O}}-) \mathrm{O}^{(2) \mathrm{M}} \ngtr \mathrm{O}^{1 \mathrm{~S}}$ \\
\hline
\end{tabular}

$16 \mathrm{O}^{2 \mathrm{P}}$ eta $\mathrm{O}^{1 \mathrm{~S}}$ artean muga bat dago, sarri egun batetik hurrengora doana gutxienez.

17 Grafikoek adierazten duten interpretazioa iraganaldiko gertaera gertagarri batena da. Baretuan bertikal berean doaz azken $\mathrm{O}$ biak, errealean, horizontal berean, azken O-a beste bien artean. 
Euskararen tempus-aspektu-modu sistemaren trataera formala

\begin{tabular}{|c|c|}
\hline \pm FAR & $\begin{array}{l}\text { gertaeraren gaineko aspektu ikuspegia } \mathrm{O}^{\mathrm{P}} \text { edo } \mathrm{O}^{\mathrm{V}} \text { orientazio- } \\
\text { puntuen eremuan ainguratuta dagoela edo ez (baizik eta } \mathrm{O}^{1 \mathrm{~S}} \text { - } \\
\text { arenean ainguratuta dagoela) adierazten duen operatzailea }\end{array}$ \\
\hline+ FAR & $={ }_{\text {def }}(\hat{O}-) \mathrm{O}^{\mathrm{P}} \vee(\hat{\mathrm{O}}-) \mathrm{O}^{\mathrm{V}}$ \\
\hline IRAGANALDIAN (ô) & $\begin{array}{l}\text { Predikatu honek adierazten du Ô orientazio-puntua iraga- } \\
\text { naldian kokatuta dagoela, hots (artez edo zenbait urratsetan } \\
\text { zehar), } \mathrm{O}^{2 \mathrm{P}} \text {-ri lotuta dagoela }\end{array}$ \\
\hline IRAGANALDIAN (ô) & $==_{\text {def }}(\hat{\mathrm{O}}-) \mathrm{O}^{2 \mathrm{P}}$ \\
\hline ALEGIGUNEAN (ô) & $\begin{array}{l}\text { Ô orientazio-puntua alegigunean kokatuta dagoela adieraz- } \\
\text { teko predikatua, hots (artez edo zenbait urratsetan zehar) } \\
\mathrm{O}^{2 \mathrm{~V}} \text {-ri lotuta }\end{array}$ \\
\hline ALEGIGUNEAN (ô) & $={ }_{\text {def }}(\hat{O}-) \mathrm{O}^{2 \mathrm{~V}}$ \\
\hline -FAR & $={ }_{\text {def }} \hat{O}^{1 S} \vee\left((\hat{O}-) \mathrm{O}^{1 S} \wedge \neg\left((\hat{O}-) \mathrm{O}^{\mathrm{P}} \vee(\hat{\mathrm{O}}-) \mathrm{O}^{\mathrm{V}}\right)\right.$ \\
\hline ORAINGUNEAN (ô) & $\begin{array}{l}\text { Ô orientazio-puntua hizketa-guneari lotuta dagoela adieraz- } \\
\text { teko predikatua }\end{array}$ \\
\hline ORAINGUNEAN (ô) & $={ }_{\text {def }} \hat{O}^{1 S} \vee\left((\hat{O}-) \mathrm{O}^{\mathrm{M}} \rightarrow(\hat{\mathrm{O}}-) \mathrm{O}^{1 \mathrm{~S}}\right)$ \\
\hline ORAINGUNEAN (ô) & $==_{\text {def }}-\mathrm{FAR}$ \\
\hline$< \pm$ urruna $>$ & $\begin{array}{l}\text { adizkia gai morfologiko urrunekoa edo hurbilekoa izatearen } \\
\text { adierazpena }\end{array}$ \\
\hline Postulatua & $<+$ urruna $>\leftrightarrow+$ FAR \\
\hline
\end{tabular}

Irreal modura aurkezturiko gertaerak aurki daitezke morfologikoki markaturiko hiru ainguratze-eremuetan, baina urrunetakoez bakarrik esango dugu «alegiazkoak» direla. Honek azaltzen du, pace Euskaltzaindia [10], zergatik diren gramatikalak honelako esamoldeak: prezioa jakin balu erosiko zukeen ${ }^{18}$ (ikusi 15. taula eta 17. irudia).

15. taula. Alegiazkotasuna.

\begin{tabular}{c|l}
\hline [ALEGIAZKOA $]$ & $=_{\text {def }}+\mathrm{FAR} \wedge[+$ irrealis $]$ \\
\hline \multirow{2}{*}{ Teorema ondorioztagarriak } & $\left((\hat{\mathrm{O}}-) \mathrm{O}^{2 \mathrm{~V}}\right) \rightarrow[$ ALEGIAZKOA $]$ \\
\cline { 2 - 2 } & $\left(\left((\hat{\mathrm{O}}-) \mathrm{O}^{2 \mathrm{~V}}\right) \rightarrow(+\mathrm{FAR} \wedge[+\right.$ irrealis $])$ \\
\hline
\end{tabular}

18 Bide desberdinez, baina egitura biek kokatzen dituzte dagozkien gertaerak eremu berean, alegigunean eta oraingo hizketa-gunea baino lehen. 


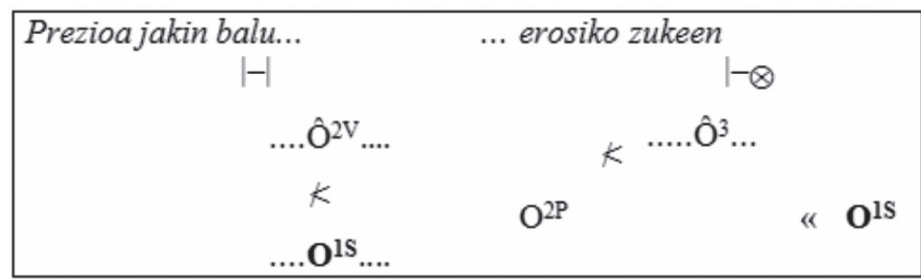

17. irudia. Irudikatze grafikoen adibideak (XI): alegiazkoak.

Hala ere, alegigunean ez daukagu gertaerak erreal gisa aurkezterik. Horregatik, irrealtasun faktoreren bati loturiko bestelako marka semantikorik ez badaramate, alegiguneko zenbait adizkik ahalezko interpretazioa jaso behar dute (liro, lei...), eta beste batzuek (liranak, luena...) $<+(t e) k e>($ eta $+\mathrm{PRO})$ baliokoen alomorfotzat jo behar dira (liratekeenak, lukeena...).

Gertaera errealak orainguneari edo iraganaldiari dagozkio. Areago, iraganaldiaren eremua bera beste kokagune hertsiago baten zabalpentzat har, erraltzat jotako iraganeko gertaeren eremuaren zabalpentzat. Izan ere, iraganaldiko adizki guztiek behar dute - $n$ marka bat eta honen esanahia hitzemate neustikoaren terminoetan eman daiteke: hitzemate neustiko arruntaren marka esplizitua da, gertaerari berari erreferentzialki seinalatzeko edo «so eragiteko» bide bat, hala nola subjuntiboko osagarrietan (sar zaitezen espero dut) (ikusi 18. irudia).

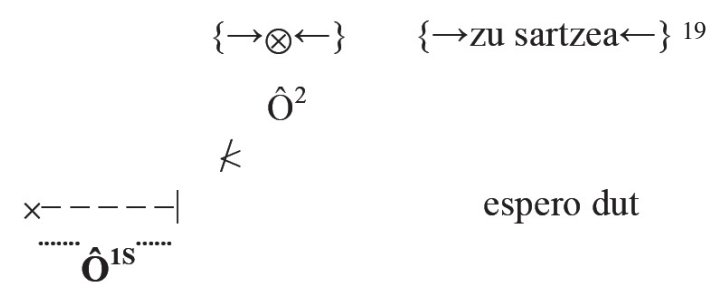

18. irudia. Subjuntiboa: Sar zaitezen espero dut.

Halakorik ez dute behar orainguneko adizkiek, bestelako balio neustikoaren markarik ez izan arren, baldin erabilera independentea onartzen badute (Hareren terminoetan balio klistiko independentea badute; nire formalizazioan, inoiz operatzaile neustiko baten aurre- eta goi-indize gisa jarrita, $-\kappa \mathrm{DEP})$ (ikusi 16. taula).

19 Giltzek adierazten dute menpeko balio klistikoa. 
Euskararen tempus-aspektu-modu sistemaren trataera formala

16. taula. Balio klistikoak eta hitzemate neustiko esplizituki markatua.

\begin{tabular}{c|l}
\hline \pm KDEP & $\begin{array}{c}\text { adizkia dagoen perpausaren menpeko erabilera / erabi- } \\
\text { lera independentea izatearen adierazpena }\end{array}$ \\
\hline \pm SO ERAGILEA & $\begin{array}{l}\text { aditz-esapideak adierazitako gertaera erreferentzialki } \\
\text { seinalatua edo identifikatua izatearen / ez izatearen } \\
\text { adierazpena }\end{array}$ \\
\hline$< \pm n>$ & $-n$ hizkiaren agerpenaren / agerpen ezaren adierazpena \\
\hline Postulatua & $<+n>\rightarrow+$ SO ERAGILEA \\
\hline N-OPERATZAILEA: & $\begin{array}{l}\text { TAM sistemako zenbait operatzaileren (operatzaile } \\
\ll \text { neustikoen») ordezko meta-etiketa }\end{array}$ \\
\hline Postulatua & $\begin{array}{l} \pm \text { N-OPERATZAILEA } \leftrightarrow( \pm \text { BARETUA } \vee \pm S U B \text { IUD } \\
\text { ICE } \vee \pm \text { AIPAMENA } \vee \pm \text { SO ERAGILEA) }\end{array}$ \\
\hline \pm DDEP + N-OPERATZAILEA: & $\begin{array}{l}\text { halako operatzaileak }+\kappa \text { KDEP balio klistikoa dakarrela } \\
\text { edo ez dakarrela adierazteko notazioa }\end{array}$ \\
\hline
\end{tabular}

Badute behar, aldiz, erabilera menpekodun erlatibozko adizkiek, batetik, eta, bestetik, oraingunearen aktualitatetik urrundutakoek baina errealtzat jotako $\mathrm{O}^{2 \mathrm{P}}$-ra ainguratuek, hots, iraganeko zein iraganaldikoek. Bestalde, alegiazko $\mathrm{O}^{2 \mathrm{~V}}$-ra ainguratuen artean, gehienek badute aldaera neustikoren bat, baina salbuespena dira hirugarren pertsonari zuzendutako zenbait aginte-adizki (bedi, bezate...): balizko hizketa-gunean oraingokoaren hirugarren pertsona bigarren pertsona liteke (Ikusi 19. irudia).

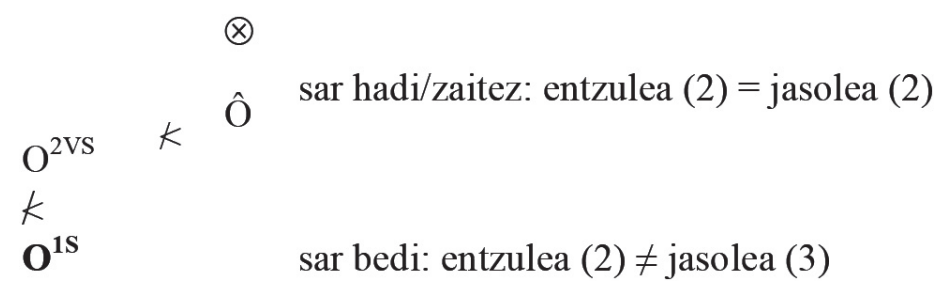

19. irudia. Gai urruneko aginte-adizkien zentzua: Sar bedi!

Zehazki, +FAR, +SO ERAGILEA eta $-\kappa$ DEP balioen konbinaketa halabeharrezkoa da gertaerak $\mathrm{O}^{(2) \mathrm{P}}$-ren inguruan ainguratzeko. -FAR, +SO ERAGILEA eta - $\mathrm{\kappa DEP}$ balioekin, aldiz, zentzu hortatiboko adizkiak sortzen dira. Lehen pertsonako hortatiboek, bereziki baina ez haiek bakarrik, molde hori erabili behar dute (goazen!...) (Ikusi 17. taula eta 20. irudia). 
17. taula. ${ }^{-\kappa D E P}+$ SO ERAGILEA balioaren inplikazioak.

\begin{tabular}{|c|c|}
\hline \multirow{4}{*}{ Postulatuak } & $\begin{array}{l}-\mathrm{kDEP}+\mathrm{SO} \text { ERAGILEA } \rightarrow \quad\left(\left({ }^{-\kappa D E P}+\mathrm{SO} \text { ERAGI- }\right.\right. \\
\left.\mathrm{LEA} \wedge[+ \text { +deskr }]) \vee\left({ }^{-\mathrm{kDEP}}+\mathrm{SO} \text { ERAGILEA } \wedge[- \text {-deskr }]\right)\right)\end{array}$ \\
\hline & $\left([+\right.$ deskr $] \wedge^{-\mathrm{kDEP}}+\mathrm{SO}$ ERAGILEA $) \leftrightarrow \operatorname{IRAGANALDIAN}(\hat{\mathrm{O}})$ \\
\hline & $\begin{array}{l}{[\text {-irrealis }] \leftrightarrow(-\mathrm{BARETUA} \wedge-\text { SUB IUDICE } \wedge[\text {-ahal }] \wedge[\text {-as- }} \\
\text { mozkoa }] \wedge[+ \text { deskr }] \wedge\left(-\mathrm{FAR} \vee\left(+\mathrm{FAR} \wedge{ }^{-\mathrm{kDEP}}+\mathrm{SO} \text { ERAGI- }\right.\right. \\
\text { LEA })))\end{array}$ \\
\hline & $\operatorname{IRAGANALDIAN}(\hat{O}) \leftrightarrow\left(+\mathrm{FAR} \wedge^{-\mathrm{KDEP}}+\mathrm{SO}\right.$ ERAGILEA $\left.)\right)$ \\
\hline \multirow{2}{*}{$\begin{array}{c}\text { Teorema } \\
\text { ondoriozta-garriak }\end{array}$} & $\begin{array}{l}{[+ \text { irrealis }] \leftrightarrow(+\mathrm{BARETUA} \vee+\text { SUB IUDICE } \vee \text { [+asmoz- }} \\
\text { koa] } \vee[+ \text { ahal }] \vee[\text {-deskr }] \vee\left(+\mathrm{FAR} \wedge \neg\left({ }^{-\mathrm{kDEP}}+\mathrm{SO} \text { ERAGI- }\right.\right. \\
\text { LEA })))\end{array}$ \\
\hline & $\begin{array}{l}\text { ALEGIGUNEAN }(\hat{O}) \leftrightarrow(+\mathrm{BARETUA} \vee+S U B \text { IUDICE } \vee \text { [+as- } \\
\text { mozkoa }] \vee[+ \text { ahal }] \vee[- \text { deskr }] \vee\left(+\mathrm{FAR} \wedge \neg\left({ }^{-\mathrm{kDEP}}+\mathrm{SO} \text { ERAGI- }\right.\right. \\
\text { LEA })))\end{array}$ \\
\hline
\end{tabular}

$$
\begin{aligned}
& \mathbf{O}^{\mathbf{1 S}} \quad k \\
& \hat{\mathrm{O}}^{2}
\end{aligned}
$$

20. irudia. Lehen pertsonako hortatiboak: Isil gaitezen!

Bada aginte-adizkiak sortzeko beste adibide bat, bai hirugarren personan (sar daitezela!), baita (edozein pertsonako) ezezkoetan ere (ez nadila engaina!). Bide hau +AIPAMENA balioko -la atzizkiak eskaintzen du, aipamenak berez ainguratzen baitu ikuspegia bigarren hizketa-gune batera. Bertan, oraingo hirugarren pertsona dena bigarrena litzateke. Erabilera independentea duten aipamenezko aditz-esaerek ez dute beste interpretaziorik. Segidan doaz hastapen teoriko esplizituak, eta haien ondoren adierazpen grafikoak (ikusi 18. taula eta 21-27. irudiak).

${ }^{20}$ Geziek +SO ERAGILEA balioa irudikatzen dute. 
18. taula. \pm AIPAMENA balioak.

\begin{tabular}{|c|c|}
\hline \pm AIPAMENA & $\begin{array}{l}\text { adizkiaren bidez beste esaera bat errepikatu edo hori sortzeko ja- } \\
\text { rraibideak ematearen / ez ematearen adierazpena }\end{array}$ \\
\hline$< \pm l a>$ & -la hizkiaren agerpenarena / agerpen ezaren adierazpena \\
\hline Postulatua & $<+l a>\leftrightarrow+$ AIPAMENA \\
\hline$< \pm e z>$ & $\begin{array}{l}\text { adizkia ezezkoa ( } e z \text { partikulari lotutakoa) izatearen / ez izatearen } \\
\text { adierazpena }\end{array}$ \\
\hline \multirow{3}{*}{ Postulatuak } & $\begin{array}{l}([\text { HORTATIBOA }] \wedge(1 . S \vee 1 . A \vee(3 . P \wedge \text { IMPR.A })) \rightarrow(+ \text { SO ERA } \\
\text { GILEA } \vee(+ \text { AIPAMENA } \wedge<+e z>))^{21}\end{array}$ \\
\hline & $([$ HORTATIBOA $] \wedge(3 . S \vee 3 . A)) \rightarrow\left((\hat{O} \ngtr) \mathrm{O}^{2 S} \ngtr \mathrm{O}^{1 \mathrm{~S}}\right)$ \\
\hline & -KDEP +AIPAMENA $\leftrightarrow[$ HORTATIBOA] $)$ \\
\hline
\end{tabular}

21. irudia. Indikatiboko aipamenezko egituren zentzua: Uste dut etorri dela.

$$
\begin{aligned}
& \text { “®" “sar hadi" } \\
& \mathrm{O}^{3} \\
& \begin{array}{l}
K \\
\mathrm{O}^{2 \mathrm{~S}}
\end{array} \quad \text { entzulea }(2)=\text { jasolea }(2) \\
& \text { k } \\
& \mathbf{O}^{1 \mathbf{S}} \quad \text { entzulea }(2) \neq \text { jasolea (3) }
\end{aligned}
$$

22. irudia. Aipamenezko aginte-adizkien zentzua: Sar dadila!

$21 \mathrm{~S}$ : aditz iragangaitz baten «subjektua». A: aditz iragankor baten egile (agent) gisako argumentua. P: aditz iragankor baten jasaile (patient) gisako argumentua. IMPR: Inpertsonala.

22 Komatxoek aipamena adierazten dute. 


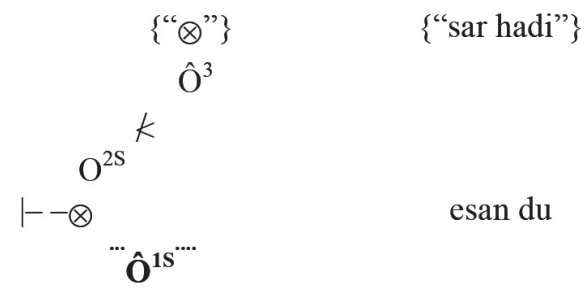

23. irudia. Hortatibo baten aipamena: Sar dadila esan $d u$.

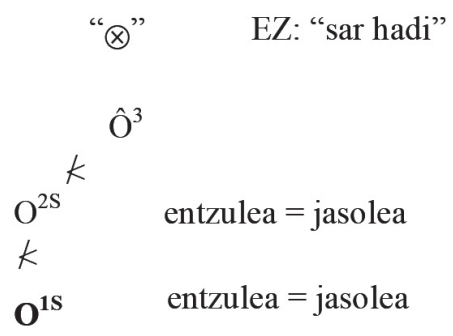

24. irudia. Ezezko aipamezko hortatiboak: Ez hadila sar!

$$
\begin{aligned}
& \{“ \mid--\otimes "\} \quad \text { \{"hatorkio"\} } \\
& \hat{\mathrm{O}}^{3} \\
& \text { k } \\
& 1--\otimes \quad \text { esaiozu } \\
& \hat{\mathrm{O}}^{2 \mathrm{~S}} \\
& \text { k } \\
& \mathbf{O}^{\mathbf{1 s}}
\end{aligned}
$$

25. irudia. Hortatibo bat transmititzeko hortatibo esplizitua (I): Datorkidala esaiozu!

$$
\begin{aligned}
& \{“ \otimes "\} \quad \text { \{"harriok, egin } \\
& \text { zaitezte ogi"\} } \\
& \hat{O}^{3} \\
& \text { k } \\
& 1--\otimes \quad \text { errak } \\
& \hat{O}^{2 \mathrm{~S}} \\
& k \\
& \mathrm{O}^{1 \mathrm{~S}}
\end{aligned}
$$

26. irudia. Hortatibo bat transmititzeko hortatibo esplizitua (II): Errak harri hauek ogi egin daitezela! 


$$
\begin{aligned}
& \{\rightarrow \otimes \leftarrow\} \quad\{\rightarrow \text { harri hauek } \\
& \text { ogi egitea } \leftarrow\} \\
& \hat{O}^{3} \\
& \text { k } \\
& 1--\otimes \quad \text { errak } \\
& \hat{\mathrm{O}}^{2 \mathrm{~S}} \\
& \text { k } \\
& \mathbf{O}^{1 \mathrm{~s}}
\end{aligned}
$$

27. irudia. Gertaera baterako hortaziora deitzea: Errak harri hauek ogi egin daitezen!

Egungo euskaran $+\mathrm{AD}$ balioak berez dakar ikuspegiaren proiekzioa geroan, XVII. mendetik hona, haren $\mathrm{O}^{(1) S}$-rekiko bateraezintasuna hedatu egin baitzen $\mathrm{O}^{(2) \mathrm{P}}$ eta $\mathrm{O}^{(2) \mathrm{V}}$-ra. Hipotesi hau nahikoa dugu azaltzeko XVI. mendera arteko aoristo zaharraren galera (orduko ikus zezan $\approx$ egungo ikusi zuen) (ikusi 19. taula).

19. taula. $+\mathrm{AD}$ balioak dakarren ikuspegiaren proiekzioa geroan eta aoristo zaharraren galera.

\begin{tabular}{c|l}
\hline $\begin{array}{c}\text { Postulatuak } \\
\text { (xVII. mendetik hona })\end{array}$ & $\begin{array}{l}+\mathrm{AD} \rightarrow\left(\left(\mathrm{O}^{\mathrm{Mn}}\left\langle\hat{\mathrm{O}}^{\mathrm{n}+1}\right) \vee\left(\mathrm{O}^{\mathrm{M}}\left(-\mathrm{O}^{\mathrm{n}}\right)\left\langle\hat{\mathrm{O}}^{\mathrm{n}+1}\right)\right.\right.\right. \\
+\mathrm{AD} \rightarrow(+\mathrm{KDEP} \vee[+ \text { ahal }] \vee+\mathrm{BARETUA} \vee[- \text { deskr }])\end{array}$ \\
\hline \multirow{4}{*}{$\begin{array}{c}\text { Teorema } \\
\text { ondorioztagarriak }\end{array}$} & $\begin{array}{l}(\mathrm{XVII} . \text { mendetik hona }) \\
+\mathrm{AD} \rightarrow\left(\mathrm{O}^{\mathrm{M}} \neq \hat{\mathrm{O}}\right)\end{array}$ \\
\cline { 2 - 2 } & $+\mathrm{AD} \rightarrow\left(\mathrm{O}^{\mathrm{M}}><\hat{\mathrm{O}}\right)$ \\
\cline { 2 - 2 } & $\begin{array}{l}(\mathrm{XVII} . \text { mendetik hona }) \\
+\mathrm{AD} \rightarrow \text { GEROKOA }\left(\hat{\mathrm{O}}^{\mathrm{n}+\mathrm{m}}, \mathrm{O}^{\mathrm{Mn}}\right)\end{array}$ \\
\hline
\end{tabular}

Taula horren bigarren errenkadakoa erraz nahas daiteke [+irrealis] balioarekin, zeren eta $+\kappa D E P$ balioko erabilera gehienetan [+asmozkoa] balioa agertzen baita, baina geroko gertaera errealak adieraz daitezke $+\mathrm{AD}$ adizkien bidez, ageriago iraganaldian (ez zegoen eragozterik etor zitezen). *EDIN eta *EZAN aditzek badituzte, beraz, indikatiboko formak. Euskararen gramatikariek erabili izan ohi duten «indikatibo» izendapena ez dagokio espero litekeenari, gertaera errealak adierazteko moduari, baizik eta beste zerbaiti (*EDIN eta *EZAN aditzen forma guztiak hortik kanpoan laga baitira). Benetako «indikatiboa» eta euskararen gramatikariena («EGINDIKATIBOA») bereiz daitezke, honela (ikusi 20. taula). 
20. taula. Benetako indikatiboa eta euskararen gramatikariena.

\begin{tabular}{c|l}
\hline [INDIKATIBOA $]$ & gertaerak errealtzat aurkezteko aditz-modua \\
\hline [EG-INDIKATIBOA $]$ & + AD aspektu-operatzaileaz kanpoko adizkien ezaugarria \\
\hline
\end{tabular}

Erabili izan diren bestelako etiketak $[11,12]$ atal honetan ikusitako faktore semantikoen terminoetan azal daitezke (Ikusi 21. taula).

21. taula. Ohiko zenbait etiketa gramatikalen azalpena hemengo termino semantikoetan.

\begin{tabular}{|c|c|}
\hline [SUBJUNTIBOA] & $\begin{array}{l}\text { menpeko balio klistikoaren eragileek modu hau ezartzen } \\
\text { dute baldin aspektu ikuspegia gertaera barruan edo gertaerari } \\
\text { lotuta kokatzen badute eta ikuspegi hori gerokoa bada, hots, } \\
\text { GEROKOA }\left(\hat{O}^{n+m}, \mathrm{O}^{\mathrm{n}}\right)\end{array}$ \\
\hline [KONJUNTIBOA] & $\begin{array}{l}\text { hitzemate neustikoa periferiara edo menpeko balio klistikoko } \\
\text { esapideetara eramatearen eragiketaren (edo haren gabeziaren) } \\
\text { adierazpena }\end{array}$ \\
\hline [KONJUNTIBOA] & $={ }_{\text {def }}(+\kappa D E P+S O$ ERAGILEA $\vee+\kappa$ DEP + AIPAMENA $)$ \\
\hline [BALDINERA] & $\begin{array}{l}\text { hitzemate neustikoa ondorio bati begira iritzipean jartzen dela } \\
\text { adierazteko aditz-modu edo aditz-modalitatea }\end{array}$ \\
\hline [BALDINERA] & $==_{\mathrm{def}}+\mathrm{kDEP}+S U B$ IUDICE \\
\hline [OPTATIBOA] & $\begin{array}{l}\text { hitzemate neustikoa inolako ondoriori begiratu gabe iritzipean } \\
\text { jartzen dela adierazteko aditz-modu edo aditz-modalitatea }\end{array}$ \\
\hline [OPTATIBOA] & $={ }_{\mathrm{def}}-\mathrm{kDEP}+S U B$ IUDICE \\
\hline [AIERUERA] & $\begin{array}{l}\text { [+deskr] balio tropikoko frastikoa erabateko ziurtasunik gabe } \\
\text { adierazteko modua }\end{array}$ \\
\hline [AIERUERA] & $==_{\text {def }}+$ BARETUA $\wedge[+$ deskr $] \wedge[-$ ahal $]$ \\
\hline [AHALERA] & $\begin{array}{l}\text { gertaera errotiko ahalezkotzat adierazteko aditz-modu edo } \\
\text { aditz-modalitatea }\end{array}$ \\
\hline Postulatua & {$[$ AHALERA $] \leftrightarrow[+$ ahal $]$} \\
\hline
\end{tabular}

Modu edo modalitate horiek zenbait marka morfologiko dituzte. Hona hemen orain arte agertu ez direnak (ikusi 22. taula): 
22. taula. Moduen / modalitateen markatzaile morfologikoak.

\begin{tabular}{|c|c|}
\hline$< \pm$ ba $>$ & $b a$ - hizkiaren agerpenaren / agerpen ezaren adierazpena \\
\hline \multirow{3}{*}{ Postulatuak } & $<+b a>\rightarrow+$ SUB IUDICE \\
\hline & $<+b a>\rightarrow([\mathrm{BALDINERA}] \vee[$ OPTATIBOA] $)$ \\
\hline & $(<+b a>\wedge[$ OPTATIBOA] $) \rightarrow$ ALEGIGUNEAN $(\hat{O})$ \\
\hline$< \pm \operatorname{ai}(\mathrm{t})>$ & $\begin{array}{l}\text { ai }(t) \text { - hizkiaren (edo +PRO operatzaileari loturiko } a(h a) l \\
\text { partikularen) agerpenaren / agerpen ezaren adierazpena }\end{array}$ \\
\hline \multirow{4}{*}{ Postulatuak } & $<+a i(t)>\rightarrow+S U B$ IUDICE \\
\hline & $<+a i(t)>\rightarrow-\kappa \mathrm{DEP}$ \\
\hline & $+S U B I U D I C E \leftrightarrow(<+b a>\vee<+a i(t)>)$ \\
\hline & $(<+a i(t)>\wedge$ [OPTATIBOA] $) \rightarrow$ ALEGIGUNEAN(Ô) \\
\hline$< \pm$ bait $>$ & bait- hizkiaren agerpenaren / agerpen ezaren adierazpena \\
\hline \multirow{3}{*}{ Postulatuak } & $<+$ bait $>\rightarrow+\kappa \mathrm{DEP}$ \\
\hline & $<+$ bait $>\rightarrow+$ SO ERAGILEA \\
\hline & + SO ERAGILEA $\leftrightarrow(<+n>\vee<+$ bait $>)$ \\
\hline$< \pm$ ahal $>$ & $\begin{array}{l}\text { gertaerak errotiko ahalezkotzat aurkeztearen / ez aurkeztea- } \\
\text { ren adierazpen lexikala ( } \text { hal, ezin, baita garai batetik hona } \\
\text { *IRON eta EGIN aditzen formak ere) }\end{array}$ \\
\hline Postulatua & $<+$ ahal $>\rightarrow[+$ ahal $]$ \\
\hline $\begin{array}{l}\text { Id. } \\
\text { (Euskara klasikorako) }\end{array}$ & $(+\mathrm{AD} \wedge<+($ te $) k e>) \rightarrow([+$ ahal $] \rightarrow<+$ ahal $>)$ \\
\hline \multirow{6}{*}{ Id. (orokorrak) } & {$[+$ ahal $] \rightarrow((+\mathrm{AD} \wedge<+($ te $) k e>) \vee<+$ ahal $>)$} \\
\hline & $(+\mathrm{AD} \wedge[+$ ahal $]) \rightarrow-\mathrm{BARETUA}$ \\
\hline & $<+($ te $) k e>\rightarrow(+\mathrm{PRO} \vee[+$ ahal $])$ \\
\hline & + BARETUA $\rightarrow+$ PRO \\
\hline & $(<+(t e) k e>\wedge(+\mathrm{AD} \vee+\mathrm{FAR})) \rightarrow(+\mathrm{BARETUA} \vee[+\mathrm{ahal}])$ \\
\hline & $(<+(t e) k e>\wedge[+\mathrm{deskr}] \wedge+\mathrm{AD} \wedge-\mathrm{FAR}) \rightarrow[$ AHALERA $]$ \\
\hline
\end{tabular}




\section{ONDORIO GISA: EUSKAL ADITZ JOKATUAREN TAM SISTEMAREN IKUSPEGI OROKORRA}

Aurreko ataletako osagaiez ikuspegi orokor bat era daiteke modu / modalitate bakoitzaren faktore semantikoez (ikusi 23. taula):

23. taula. Aditz-moduen sailkapena dagozkien balio neustiko, klistiko eta tropikoen arabera.

\begin{tabular}{|c|c|c|c|c|c|c|}
\hline \multirow{3}{*}{$\begin{array}{c}\text { BALIO } \\
\text { NEUSTIKOA } \rightarrow \\
\text { BALIO } \\
\text { KLISTIKOA } \rightarrow\end{array}$} & \multicolumn{4}{|c|}{-SUB IUDICE } & \multirow{2}{*}{\multicolumn{2}{|c|}{ + SUB IUDICE }} \\
\hline & \multicolumn{2}{|c|}{-BARETUA } & \multicolumn{2}{|c|}{$\begin{array}{c}\text { +BARETUA } \\
\text { (BALDINTZAPEAN EDO EZ) }\end{array}$} & & \\
\hline & \multirow[b]{2}{*}{$-\kappa \mathrm{DEP}$} & \multirow[b]{2}{*}{$+\kappa \mathrm{DEP}$} & \multirow[b]{2}{*}{$-\kappa D E P$} & \multirow[b]{2}{*}{$+\kappa D E P$} & \multirow[b]{2}{*}{$-\kappa D E P$} & \multirow[b]{2}{*}{$+\kappa D E P$} \\
\hline $\begin{array}{c}\text { TROPIKOAREN } \\
\text { BALIOA } \\
\downarrow\end{array}$ & & & & & & \\
\hline [+deskr] & Indikatiboa & $\begin{array}{c}\text { Indikatiboaren } \\
\text { konjuntiboa } \\
\text { Subjuntiboa } \\
\text { (GEROKOA) }\end{array}$ & $\begin{array}{c}\text { Aieruera } \\
\text { Ahalera } \\
(+\mathrm{AD} \vee<+ \text { ahal }>)\end{array}$ & $\begin{array}{c}\text { Aierueraren } \\
\text { eta ahaleraren } \\
\text { konjuntiboak }\end{array}$ & $\begin{array}{l}\text { Optatiboa } \\
\quad(\text { edo } \\
\text { «botiboa») }\end{array}$ & Baldinera \\
\hline $\begin{array}{l}\text { [-deskr] } \\
(+\mathrm{AD})\end{array}$ & Hortatiboa & & $\begin{array}{l}\text { Hortatibo } \\
\text { baretua }\end{array}$ & & & \\
\hline
\end{tabular}


Bestelako bereizketak hemendik datoz: GEROKO predikatuaren eta [ \pm irrealis] eta \pm FAR balioen konbinaketatik (ikusi 24. taula).

24. taula. Aditzen modu-aldi sailkapena.

\begin{tabular}{|c|c|c|c|c|c|c|}
\hline & & \multirow{3}{*}{ [-irrealis] } & \multicolumn{4}{|c|}{ [+irrealis] } \\
\hline & & & \multicolumn{2}{|c|}{ Aldaera neustikoak } & \multirow[b]{2}{*}{ [+ahal] } & \multirow[b]{2}{*}{ [+asmozkoa] } \\
\hline & & & + +SUB IUDICE & $\begin{array}{c}\text { +BARETUA } \\
\text { (BALDINTZA-PEAN } \\
\text { EDO EZ) }\end{array}$ & & \\
\hline \multirow{2}{*}{ 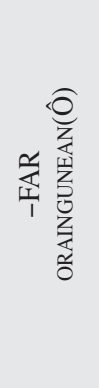 } & $\begin{array}{l}\varangle \\
0 \\
y \\
0 \\
\frac{1}{11} \\
0\end{array}$ & $\begin{array}{l}\text { Orainguneko } \\
\text { indikatiboa }\end{array}$ & \multirow{2}{*}{$\begin{array}{l}\text { Orainguneko } \\
\text { baldinera, } \\
\text { optatiboa }\end{array}$} & $\begin{array}{l}\text { Orainguneko } \\
\text { aieruera }\end{array}$ & & \\
\hline & $\begin{array}{l}\varangle \\
0 \\
\frac{1}{0} \\
\frac{1}{1} \\
0\end{array}$ & $\begin{array}{c}\text { Orainguneko } \\
\text { indikatiboko } \\
\text { ondorengoa } \\
\text { («geroaldia») eta } \\
\text { subjuntibo erreala }\end{array}$ & & $\begin{array}{c}\text { Orainguneko } \\
\text { aieruera, } \\
\text { «geroaldi arkaikoa» }\end{array}$ & $\begin{array}{l}\text { Orainguneko } \\
\text { ahalera }\end{array}$ & $\begin{array}{l}\text { Orainguneko } \\
\text { subjuntiboa, } \\
\text { agintera }\end{array}$ \\
\hline \multirow{2}{*}{ 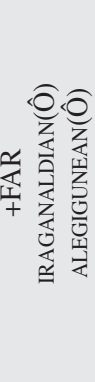 } & 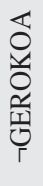 & $\begin{array}{l}\text { Iraganaldiko } \\
\text { indikatiboa }\end{array}$ & \multirow{2}{*}{$\begin{array}{l}\text { Alegiazko } \\
\text { baldinera, } \\
\text { optatiboa }\end{array}$} & $\begin{array}{l}\text { Alegiazko } \\
\text { aieruera }\end{array}$ & & \\
\hline & 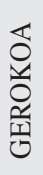 & $\begin{array}{c}\text { Iraganaldiko } \\
\text { ondorengoa } \\
\text { («geroaldia») eta } \\
\text { subjuntibo erreala }\end{array}$ & & $\begin{array}{l}\text { Alegiazko } \\
\text { aieruera }\end{array}$ & $\begin{array}{l}\text { Alegiazko } \\
\text { ahalera }\end{array}$ & $\begin{array}{l}\text { Alegiazko } \\
\text { subjuntiboa, } \\
\text { 3. pertsonako } \\
\text { gai urruneko } \\
\text { aginte-adizkiak }\end{array}$ \\
\hline
\end{tabular}


Edo, aspektu-operatzaileen terminoetan (ikusi 25. taula):

25. taula. Euskal aditz jokatuaren aspektua.

\begin{tabular}{|c|c|c|}
\hline & Oraingunea & Iraganaldia \\
\hline $\begin{array}{l}\text { Jokaera trinkoa: } \\
\text { (adizki soilak) }\end{array}$ & $\begin{array}{l}\text {-FAR }\left(+ \text { INTRA }{ }^{\mathrm{LF}}\right)^{23} \\
\text { orainekoa }^{23}\end{array}$ & $\begin{array}{l}+ \text { FAR }\left(+{ }^{+} \text {INTRA }^{\mathrm{LF}}\right) \\
\quad \text { inperfektua }\end{array}$ \\
\hline $\begin{array}{c}\text { Jokaera trinkoa: } \\
\text { (-(te)ke hizkidun adizkiak) }\end{array}$ & $\begin{array}{l}-\mathrm{FAR}\left({ }^{+}{ }^{\mathrm{INTRA}} \mathrm{A}^{\mathrm{LF}}\right) \\
\text { gerokoa }\end{array}$ & $\begin{array}{l}+ \text { FAR }\left(+ \text { INTRA }{ }^{\mathrm{LF}}\right) \\
\text { iraganaldiko geroko } \\
\text { inperfektua }\end{array}$ \\
\hline Jokaera perifrastikoa: & $\begin{array}{l}\text { orainguneko laguntzailea } \\
\text { (IZAN / *EDUN) }\end{array}$ & $\begin{array}{l}\text { iraganaldiko laguntzailea } \\
\text { (IZAN / *EDUN) }\end{array}$ \\
\hline$-t(z) e n$ (motako) partizipioa & $\begin{array}{c}\text {-FAR }\left(+ \text { INTRA }^{\mathrm{LF}}\right) \\
\text { orainekoa } \\
\text {-FAR }\left(+\mathrm{INTRA}^{\mathrm{LF}}\right)+[+ \text { ser }] \\
\text { ohiko orainekoa }\end{array}$ & 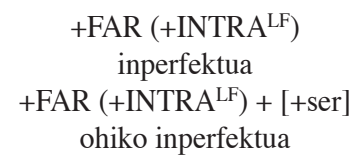 \\
\hline $\begin{array}{c}-t(z) \text { en }(\text { motako) partizipioa }+ \\
\text { ari }+\end{array}$ & $\begin{array}{l}\text {-FAR }\left(+ \text { INTRA }{ }^{\mathrm{HF}}\right) \times[+ \text { dyn }] \\
\quad \text { oraineko progresiboa }\end{array}$ & $\begin{array}{l}+ \text { FAR }\left(+\mathrm{INTRA}^{\mathrm{HF}}\right) \times[+ \text { dyn }] \\
\quad \text { iraganaldiko progresiboa }\end{array}$ \\
\hline$-t u$ (motako) partizipioa & $\begin{array}{c}\text {-FAR (-INTRA) } \\
\text {-FAR (+POSTNF / -INTRA) } \\
\text { iragan hurbila }\end{array}$ & $\begin{array}{c}\text { +FAR }(- \text { INTRA }) \\
+ \text { FAR }(+ \text { POST } \\
\text { aoristoa, iragan urruna }\end{array}$ \\
\hline -(tu)ko (motako) partizipioa & $\begin{array}{c}-\mathrm{FAR}(+\mathrm{PRO}(-\mathrm{POST})) \\
\text { gerokoa }\end{array}$ & $\begin{array}{c}+\mathrm{FAR}(+\mathrm{PRO}(-\mathrm{POST})) \\
\text { iraganaldiko gerokoa }\end{array}$ \\
\hline $\begin{array}{l}-t u \text { (motako) partizipioa } \\
\quad+a(k) /-r i k /-t a\end{array}$ & $\begin{array}{l}- \text { FAR }\left(+\mathrm{POST}^{\mathrm{HF}}\right) \\
\text { perfektua }\end{array}$ & $\begin{array}{l}+\mathrm{FAR}\left(+\mathrm{POST}{ }^{\mathrm{HF}}\right) \\
\text { pluskuanperfektua }\end{array}$ \\
\hline
\end{tabular}

23 Goiindizeak adierazten du adizki trinkoen kasuan balioa positiboa berezkoa dela eta ez markatua, jokaera perifrastikoan legez. 
Adizki jokatuen bidez adierazitako gertaerek beren kokagunea dute gertaera gaineko ikuspegi sistemaren koadro orokorrean (ikusi 26. taula):

26. taula. Morfologikoki markaturiko hiru eremuak eta modu-denbora harremanak.

\begin{tabular}{|c|c|c|c|c|c|}
\hline \multirow{3}{*}{$\begin{array}{l}\text { Irrealtasunaren } \\
\quad \text { ereтиа }\end{array}$} & \multicolumn{5}{|c|}{ ALEGIGUNEA } \\
\hline & \multicolumn{2}{|r|}{ KONTRAFAKTUALA } & \multicolumn{2}{|r|}{$\begin{array}{c}\mathrm{O}^{\mathrm{V}} \\
\text { MODU-MODALITATE ALDAERAK }\end{array}$} & \multirow{2}{*}{$\begin{array}{l}\text { GERTAGARRIA } \\
\text { GERTAGARRIA }\end{array}$} \\
\hline & $\begin{array}{l}\text { I } \\
\text { R } \\
\text { A } \\
\text { G }\end{array}$ & KONTRAFAKTU-ALA & $\begin{array}{l}\mathrm{O} \\
\mathrm{R} \\
\mathrm{A} \\
\mathrm{I}\end{array}$ & MODU-MODALITATE ALDAERAK & \\
\hline $\begin{array}{l}\qquad< \\
\text { Errealtasunaren } \\
\text { егетиа }\end{array}$ & $\begin{array}{l}\text { A } \\
\text { N } \\
\text { A } \\
\text { L } \\
\text { D } \\
\text { I } \\
\text { A }\end{array}$ & $\begin{array}{c}\mathrm{O}^{\mathrm{P}} \\
\text { IRAGANEKO URRUNA }\end{array}$ & $\begin{array}{l}\mathrm{N} \\
\mathrm{G} \\
\mathrm{U} \\
\mathrm{N} \\
\mathrm{E} \\
\mathrm{A}\end{array}$ & $\begin{array}{c}\mathrm{O}^{1 \mathrm{~S}} \\
\text { (iraganeko hurbila) }<(\text { ORAINEKOA })\end{array}$ & ONDORENGOA \\
\hline $\begin{array}{c}\uparrow \text { Modua } \\
\text { Denbora } \rightarrow\end{array}$ & & Aurrekoa « & & & $<\quad$ Gerokoa \\
\hline
\end{tabular}

Espazio urria dela eta, hemen bukatu beharra dago euskal TAM sistemaren trataera semantiko formal honen aurkezpen eskematiko hau. Harreman konplexu askoak badaude ere, haietan parte hartzen duten osagai semantiko primitiboak urriak dira oso, eta nahikoak sistemaren aldaera diakroniko eta diatopiko anitzak bere barne hartzeko eta adizki gramatikalen esanahia argitzeko baina baita gainontzeko forma posibleak zergatik ez diren gramatikalak azaltzeko ere.

\section{BIBLIOGRAFIA}

[1] Johanson L. 2000. «Viewpoint operators in European Languages». Östen Dahl (ed.) Tense and Aspect in the Languages of Europe, Mouton de Gruyter, Berlin \& New York, 27-187.

[2] Jendraschek G. 2007. La notion modale de possibilité en basque. (Morphologie, syntaxe, sémantique, variations diachronique et sociolinguistique). L'Harmattan, Paris.

[3] Hare M.R. 1964. The Language of Morals. Clarendon / OUP, Oxford. 
[4] Hare M.R. 1970. «Meaning and speech acts». Philosophical Review, 79, 324.

[5] Hare M.R. 1989. «Some Sub-Atomic Particles of Logic». Mind, 389(98), 2337.

[6] Hare M.R. 2003. Sorting Out Ethics. Oxford Scholarship Online, Oxford.

[7] Coterón I. 2015. «Euskal aditz jokatua: gertaeren gaineko ikuspegi sistema (edo TAM sistema)». Doktorego tesia, EHU, Donostia.

[8] Coterón I.. 2016. «Erbiak esan ziguna hitzen eta ekintzen gainean: Mervyn R. Harek hizketa-egintzen teoriari egindako ekarpenen emankortasuna» («The hare's story on words and actions: the fertility of R. Mervyn Hare's contribution to Speech Act Theory»). Gogoa, 14, 79-104.

[9] Searle J.R. 1975. «A taxonomy of illocutionary acts». Keith Gunderson (ed.) Language, Mind and Knowledge. University of Minnesota Press, Minneapolis, 344-369.

[10] Euskaltzaindia. 2005. Euskal gramatikaren lehen urratsak-VI. Euskaltzaindia, Bilbao.

[11] Omaechevarria, I. 1959. Euskera. Un poco de gramática y algo de morfología del verbo vasco. Icharopena, Zarautz.

[12] Lafitte P. 2008. Grammaire basque. (Navarro-Labourdin littéraire). Elkarlanean, Donostia. 